RATCLIFFE M. (2015). EXPERIENCES OF DEPRESSION: A STUDY IN PHENOMENOLOGY. OXFORD: OXFORD UNIVERSITY PRESS. 336 P. ISBN 978-0-19-960897-3*

\author{
Anna Yampolskaya \\ DSc (Philosophy), Leading Research Fellow, Centre for Fundamental Sociology, \\ National Research University Higher School of Economics \\ Address: Myasnitskaya str., 20, Moscow, Russian Federation 101000 \\ E-mail: iampolsk@gmail.com
}

Matthew Ratcliffe's book is not so much a book on depression but rather on the experience of depression - on what it means to be depressed. The book's subtitle is "a study in phenomenology", but it targets the general public as well as the academic and clinical communities. It is well written, clearly structured, informative and can serve as an excellent introduction to the phenomenology of mental illness as it illustrates the relevance of phenomenological psychopathology to philosophers, sociologists and everyone interested in the question of what constitutes a human being.

What do we mean by the word "depression"? One possible answer is that depression is what is defined as a "major depressive disorder" in Diagnostic and Statistical Manual of Mental Disorders, an authoritative and influential source published by the American Psychiatric Association, currently in its fifth edition, known as DSM-5. One could also consult International Statistical Classification of Diseases published by the World Health Organization. However, these diagnostic criteria are only used to create a "pre-understanding" of what the depressive experience consists of. Depression is used as an umbrella term to describe a whole range of heterogeneous conditions. Ratcliffe argues that all of them share a common trait: they can be characterized as troubles in the structure of experience.

Depression is more than a just mood disorder; it is first and foremost a disorder of the entire body. In certain cases (and in certain cultures), depressive patients could even be unaware that something is wrong with their mood as most of their symptoms are somatic. From the phenomenological point of view the body is our main instrument of being in the world and the medium of our experience of the world; the disorders of bodily experience in depression not only influence emotional states and cognitive abilities, they also compromise the very structure of being in the world. Ratcliffe, building on the ideas of Ludwig Binswanger, Thomas Fuchs, and Shaun Gallagher, points to a connection between bodily disorders proper to depression and the disturbances of the "sense of what the world has to offer" (p. 62).

\footnotetext{
(C) Anna Yampolskaya, 2017

(c) Centre for Fundamental Sociology, 2017 DOI: 10.17323/1728-192X-2017-4-119-124

* The publication of this paper is supported by the Basic Research Program of the National Research University Higher School of Economics.
} 
"Depression involves a disturbance of something that is fundamental to our lives, something that goes unnoticed when intact" (p. 15), it affects the most basic layer of our experience of reality. One can point out two aspects of reality: we are sure that reality is there and that we are part of it. We feel that the world is our home; that we can access the world, we can act in the world, and that a range of possibilities are open to us. This background confidence in the world and background belonging to the world is disturbed in depression, so that we gradually lose the ability to act, we no longer experience a plurality of the kinds of possibilities, as Ratcliffe puts it. According to Ratcliffe - and this is the key hypothesis of this book - it is primarily the experience of the possible that goes wrong in depression; we do not feel that certain possibilities are still open for us.

Ratcliffe holds that we actually experience the possible, and this basic experience, the experience of possibilities, underlies and conditions our access to reality, that is to say, the structure of meaning, of perception, of believing and, of course, the structure of "I can". This experience is a fundamental bodily experience that is not just there: we can and even must become aware of it, especially if it goes wrong. As Ratcliffe puts it, we can feel it, and so he calls this experience or, rather, this type of experience, "existential feelings".

Normally we feel ourselves situated in the world and involved with the world and with other people; and this sense of "situatedness" and the affective and practical involvement in the shared world is what we lack when we experience depression. Using various narratives of depression, including his own questionnaire, Ratcliffe shows very convincingly that depression is experienced not so much as sadness (as is often assumed), but rather as the poignant feeling of impotence and disconnection from the world of others that is often expressed in terms of hopelessness and guilt.

In his previous book, Feelings of Being ${ }^{1}$, where the concept of existential feelings was introduced, Ratcliffe opted for unambiguously Heideggerian thinking ${ }^{2}$. In this book, he prefers to sketch two different ways to define existential feelings - a Heideggerian one and a Husserlian one; both ways supposedly lead the reader to the same conclusion. The concept of "existential feelings" appears to generalize that of Grundstimmungen, Heideggerian fundamental moods (see p. 55-59). Ratcliffe objects to Heidegger by pointing out that fundamental moods are not integrated into the bodily experience; Ratcliffe's existential feelings are not emotions, moods or states of mind, because they are also bodily feelings. For him, there are too few examples of fundamental moods analyzed by Heidegger, and the latter does not mention the important example of awe and wonder given in Heidegger's winter semester $1937 / 1938$ lectures $^{3}$. This is not, perhaps, a mere omission; there is also a structural difference between existential feelings and fundamental moods.

1. Ratcliffe M. (2008). Feelings of Being: Phenomenology, Psychiatry, and the Sense of Reality. Oxford: Oxford University Press.

2. Ibid.. P. $41-57$.

3. Heidegger M. (1984). Gesamtausgabe, Bd. 45: Grundfragen der Philosophie: Ausgewählte "Probleme" der "Logik". Frankfurt am Main: Klostermann. S. 163-164. See also Held K. (1993). Fundamental Moods and Heidegger's Critique of Contemporary Culture // Sallis J. (ed.). Reading Heidegger: Commemorations. Bloomington: Indiana University Press. P. 292-295 and Staehler T. (2007). How is a Phenomenology of Fundamental Moods Possible? // International Journal of Philosophical Studies. Vol. 15. № 3. P. 415-433. 
It raises the question whether one can properly analyze fundamental moods in the Heideggerian context without taking into account the distinction between authentic and non-authentic modes of being in the world, which play a central role in the description of Dasein. For Heidegger, fear, anxiety and guilt are important because they force Dasein to question its own being; but for Ratcliffe the very question of authenticity falls beyond the bounds of his work, as can be seen from the final chapter where he discusses philosophical despair. Depression is a specifically human kind of suffering; however, depression makes us somewhat less human; Tolstoy's claims that the acute awareness of one's own mortality could lead one to a better understanding of the essence of human life and its meaning, are simply not plausible, says Ratcliffe.

Ratcliffe describes existential feelings as the "configurations of a possibility space" (p. 130). This possibility space has the structure of an "open horizon", which means that we do not just experience some contingent possibilities or impossibilities, but rather there are whole kinds of possibilities that are accessible to us. For example, when I see a book, I presume that it could be possible for me to get it, to move it, to read it, to enjoy it. Some of these possibilities could be void for me - for example, this particular book could be written in a foreign language or be too difficult to read. However, such an impossibility is a contingent impossibility rather than the total absence of certain kinds of possibilities. Ratcliffe uses various examples to show that in the experience of depression one is bereft of an entire class of possibilities. For example, I have lost all hope of becoming a ballerina; but this is the loss of a contingent, or intentional hope, as Ratcliffe calls it; I still could acquire another profession. The lack of what Ratcliffe calls "existential hope" is lived in a totally different manner. When somebody says that she has lost all hope in herself, it means that she believes that "nothing now can ever come to any good": all meaningful possibilities (for example, all professional paths) are closed to her forever.

The shift in existential feelings concerns the very structure of belief; as Ratcliffe puts it, "a change in existential feeling is a change in the form of experience and thought. It is not just that one's belief contents change; the way in which one believes changes too" (p. 72 , italics added).

Each act of believing is characterized by an appropriate mode of certainty; a normal course of perceptive experience presupposes a discontinuity of intuition, recurring disappointments of intention and conflicts of appearances. I can be quite sure that "this is the case"; nevertheless, my certainty always contains in itself a grain of uncertainty, as it can be "overridden" by some other experience. With one notable exception: one cannot doubt one's own experience of pain: pain, as well as any other sense-perception, cannot be disbelieved as it is neither true nor false, but is just there (cf. De anima $427 \mathrm{a}-\mathrm{b}$ ). The absence of hope and the presence of guilt in depression are as indubitable as physical pain; they are not, properly speaking, "beliefs" or "convictions" as the depressive patient does not enjoy the freedom to reject them or even to question them.

Ratcliffe is not the first researcher who examines the horrible certainty which is proper to the experience of a mental disorder. Erwin Straus suggested that hallucinations are experienced beyond any doubt because they are felt, experienced as a kind of sensation: a 
hallucinating patient is able to doubt that her soup is poisoned no more than she is able to doubt that her soup tastes salty; for her "salty" and "poisoned" belong to the same strata of reality and thus are equally indubitable $e^{4}$. Ratcliffe does not explore any possible link between existential feelings as bodily feelings and "feeling-sensations" (Gefühlsempfindungen) of the Brentano school; while he briefly compares the experience of depression and the experience of influenza, he definitely does not elaborate on the phenomenology of pain and of somatic illness. Instead he investigates the epistemic value of the aforementioned change in the structure of belief: "The conviction that one cannot recover is closely associated with something else that might otherwise be construed in terms of a belief with a specific content: the sense that 'depression reveals the world as it truly is"' (p. 69).

As a phenomenologist, I would rephrase Ratcliffe's description as follows: in depression we become slaves to the manifestation of the world, to the manner in which the world and others appear to us. Once the affective life is stuck, the world stops to evolve for us; we are no longer able to distinguish between the world and its manifestation. The depressed person partially loses her ability to interrupt or even suspend her feelings, impressions or beliefs (about the things that matter to her); the loss of free will, discussed in Chapter 6, is in fact the loss of the ability to perform epoché. His analysis shows that Seinsglaube is not a purely cognitive belief, as an unsophisticated reader of Husserl may imagine; it has a much more complex structure.

The reflective belief in the world is founded upon a pre-reflective experience of the world as a shared world, claims Ratcliffe: "If belief is construed as a matter of taking something to be the case, our 'belief' in the world's existence is not really a belief. What is interrogated through the phenomenological reduction is not just everything we take to be the case but also the sense of reality and belonging ... disturbances in this sense of 'world' are central to experiences of depression" (p. 20).

The very fact that I experience the world as being here, now, for me should not be taken for granted; my belief in the world is my trust in others. The experience of depression is rooted in the feeling of being separated from the dynamic world of others, of being incarcerated "inside a solitary, unchanging bubble" (p. 65). One realizes that the fully meaningful world of others is still somewhere there, however one is not able to connect to this there, as if one is no longer able to participate in the intersubjective constitution of time and space. As a result, one is trapped in a world where there is no proper here and now, because here and now are to be co-constituted with the others. Ratcliffe discusses alterations of the experience of time that are proper to depression, but unlike Minkowski, for whom this was a primary phenomenon, he sees them as a transformation of the possibility space. This approach proves to be extremely fruitful when it is applied to the alterations of agency which are experienced in depression. Ratcliffe shows, and very convincingly, that "the structure of our experience of freedom is changeable, and can be eroded in a number of different ways" (p. 172). He concludes that our experience of the possible is rooted in our connectedness with others, in our participation in the shared

4. Straus E. (1964). The Primary World of Senses: A Vindication of Sensory Experience. New York: London: Collier-Macmillan. P. 356-361. 
world: "... we have a reversal of Sartre's claim that the other is the death of my possibilities.' Other people do not just offer the potential to take away my possibilities. The world is experienced as a dynamic space of significant and enticing possibilities in virtue of our potential and actual relations with them" (p. 220). Ratcliffe argues that it is depression that forces me to see the other only as a threat, only as a merciless judge or as a witness of one's worthlessness; it is the feeling of being estranged from others that leads to such an impoverished view of other human beings.

Ratcliffe stresses the need to describe the experience of depression in order to explain his use of the phenomenological method, although the role of phenomenological analysis in his book is not restricted to methodology. Ratcliffe not only justifies his use of the phenomenological approach; he tries to justify phenomenology itself and thus he puts classical phenomenology on trial. He has to deal with a methodological challenge: how to apply transcendental notions to the empirical, how to speak the language of transcendental phenomenology while describing psychological realities.

Applying Husserl's notion of horizon to his descriptions of the experience of depression, Ratcliffe persistently employs the language of experienced possibilities rather than the language of constitution and/or sense-formation. Such an approach is perfectly vindicated insofar as one confines the analysis to the question of how one is dealing with the sedimented, stabilized layers of sense. However, the possibilities that constitute the whole horizon of sense are not necessarily my own and are not necessarily experienced as my own. The range of these possibilities is not restricted to the factual possibilities of any empirical subject; the transcendental concept of horizon exceeds and transcends the experience of mundane subjectivity. In Husserl's phenomenology the transcendental horizon is first and foremost the horizon of sense-formation; it is essentially linked to the productivity of sense, which is crucial to our experience of novelty. As Geniusas puts it, "the horizon's subjective reference implies the horizon's constitutive and transcendental dimensions" 5 . The practical and facultative possibilities are only part of the more complex and rich horizon structure of consciousness which always transcends itself; one cannot deduce its self-transcendence from the experienced possibilities of an empirical subject. Transcendental subjectivity can be called a blown-up subjectivity, and this refers to the dimension of sense.

From Ratcliffe's descriptions I would derive a different conclusion: depression makes one a prisoner of one's own possibilities, of one's own feelings; one cannot go beyond one's own experience because the participation in transcendental life is somehow lost. The feeling of the lack of possibilities points not just to the troubles in the structure of possibilities, it also indicates a distortion in the underlying structure of sense-formation.

In sociology "situatedness", agency and the ability to make judgments are often taken for granted, but Ratcliffe's analysis shows, and very convincingly, how fragile these key characteristics of the social actor are, how easily they can be diminished and altered, and to what extent the fundamental structures of intersubjectivity can be deformed. One has

5. Geniusas S. (2012). The Origins of the Horizon in Husserl's Phenomenology. Dordrecht: Springer. P. 95. 
to be constantly aware of these matters when studying social interactions. Mental health issues are only prevent us, human beings, from becoming a "happy and productive workforce" (as the British Cabinet Secretary Sir Jeremy Heywood gracefully put it), they also constitute a significant scientific challenge for all who do social science. I am sure that sociologists would benefit from more attention to this important and indeed pressing theoretical problem.

\title{
Рецензия: Matthew Ratcliffe. Experiences of Depression: A Study in Phenomenology (Oxford: Oxford University Press, 2015)
}

\author{
Анна Ямпольская \\ Доктор философских наук, ведущий научный сотрудник Центра фундаментальной социологии \\ Национального исследовательского университета «Высшая школа экономики» \\ Адрес: ул. Мясницкая, д. 20, Москва, Российская Федерация 101000 \\ E-mail: iampolsk@gmail.com
}

